\title{
Implementasi Motode Fuzzy Sugeno pada Pengendalian Exhoust Fan Sebagai Pembersih dan Pengatur Udara
}

\author{
1) Novriyenni \\ STMIK KAPUTAMA, JI. Veteran No. 4A-9A, Binjai, Sumatera Utara, Indonesia \\ http://www.kaputama.ac.id // Email : novri yenni@yahoo.com \\ ${ }^{2)}$ Akim Manaor Hara Pardede \\ STMIK KAPUTAMA, JI. Veteran No. 4A-9A, Binjai, Sumatera Utara, Indonesia \\ http://www.kaputama.ac.id // Email : akimmhp@livi.com \\ 3) Diky Hamdani \\ STMIK KAPUTAMA, JI. Veteran No. 4A-9A, Binjai, Sumatera Utara, Indonesia \\ http://www.kaputama.ac.id
}

\begin{abstract}
ABSTRAK
In a special room for smokers, Exhoust Fan is installed to clean the air and keep the room air fresh. Most Exhoust Fan works manually, not set automatically so that it has a constant rotational speed, so the function of the exhaust fan as an air purifier is not optimal. This study aims to apply a fuzzy method as well as to control the speed of the Exhoust Fan. Fuzzy logic will process the carbon monoxide gas which is detected by the MQ-3 sensor then the output decision maker is in the form of the Exhoust Fan rotation speed level which is exactly in accordance with the amount of carbon monoxide read by the MQ3 sensor. fuzzysugeno method can regulate the speed of putan fan based on the amount of carbon monoxide read by the MQ-3 sensor.
\end{abstract}

Kata kunci : Exhoust Fan, sensor MQ-3, logika fuzzy sugeno

\section{PENDAHULUAN}

Larangan untuk tidak merokok ditempat umum banyak diberlakukan terutama pada gedung-gedung yang menggunakan $\mathrm{AC}$, hal ini menjadi masalah bagi pera perokok berat dimana mereka sanggat ketergantungan dengan rokok. Banyak area fasilitas publik menyediakan ruang khusus untuk para perokok. Tempat merokok tersebut akan terpakai setiap hari dan akan digunakan oleh banyak perokok, oleh karena itu tempat tersebut harus dijaga kebersihannya termasuk dari segi sirkulasi udara yang masuk dalam ruangan smoking area. Pada penelitian sebelumnya yang dilakukan oleh Ferdian Agil Effendy ${ }^{[1]}$, dimana sistem telah berjalan dengan baik namun masih tidak sesuai dengan harapan. Pengontrolan terhadap kipas pembuangan berhasil dilakukan, namun masih belum akurat dalam pengukuran konsentrasi asap dikarenakan tidak menggunakan suatu metode. maka dalam penelitian ini akan dikembangkan sistem."Penerapan Metode Fuzzy Sugeno pada Pengendalian Exhaust Fan sebagai Pembersih dan Pengatur Udara". Metodefuzzy sugeno digunakan untuk mengatur hidupnya Exhaust Fan, apabila kandungan polusi udara yang dibaca oleh sensor asap, semakin meningkat, maka kecepatan Exhaust Fan akan semakin cepat. Dan apabila sensor membaca bahwa karbon monoksida di ruangan mulai menurun, maka kecepatan Exhaust Fan akan semakin lambat. Jadi kadar udara di ruangan akan berbanding lurus dengan kecepatan Exhaust Fan.

\section{BAHAN DAN METODE}

Kebutuhan dari simulasi sistem pengendalian Exhaust Fan yang akan dirancang yaituKebutuhan Desain dan metode Fuzzy sugeno.

Kebutuhan peralatan untuk membuat prototype, Adapun kebutuhan design perangkat antara lain :Kabel data USB dan kabel pelangi, Sensor MQ-3, Pipa paralon, Box plastik, Lem, Solder, Timah, Papan PCB, Beberapa baut dan mur, LED, LCD $16 \times 2$.

Kebutuhan perangkat lunak yang digunakan, lingkungan sistem operasi MSWindows2000/XP/Vista/7. Dalam perancangan ini juga menggunakan aplikasi CVAVR adalah program bahasa $C$ compiler berbasis windows untuk mikrokontroler keluarga AVR.

Flowchat sistem, Agar dapat melihat struktur jalannya program maka dibuat flowchart (diagram alur). Flowchart

Implementasi Motode Fuzzy Sugeno pada Pengendalian Exhoust Fan Sebagai Pembersih dan $\quad 88$ Pengatur Udara. Oleh : ${ }^{1)}$ Novriyenni, ${ }^{2)}$ Akim Manaor Hara Pardede, ${ }^{3)}$ Diky Hamdani 


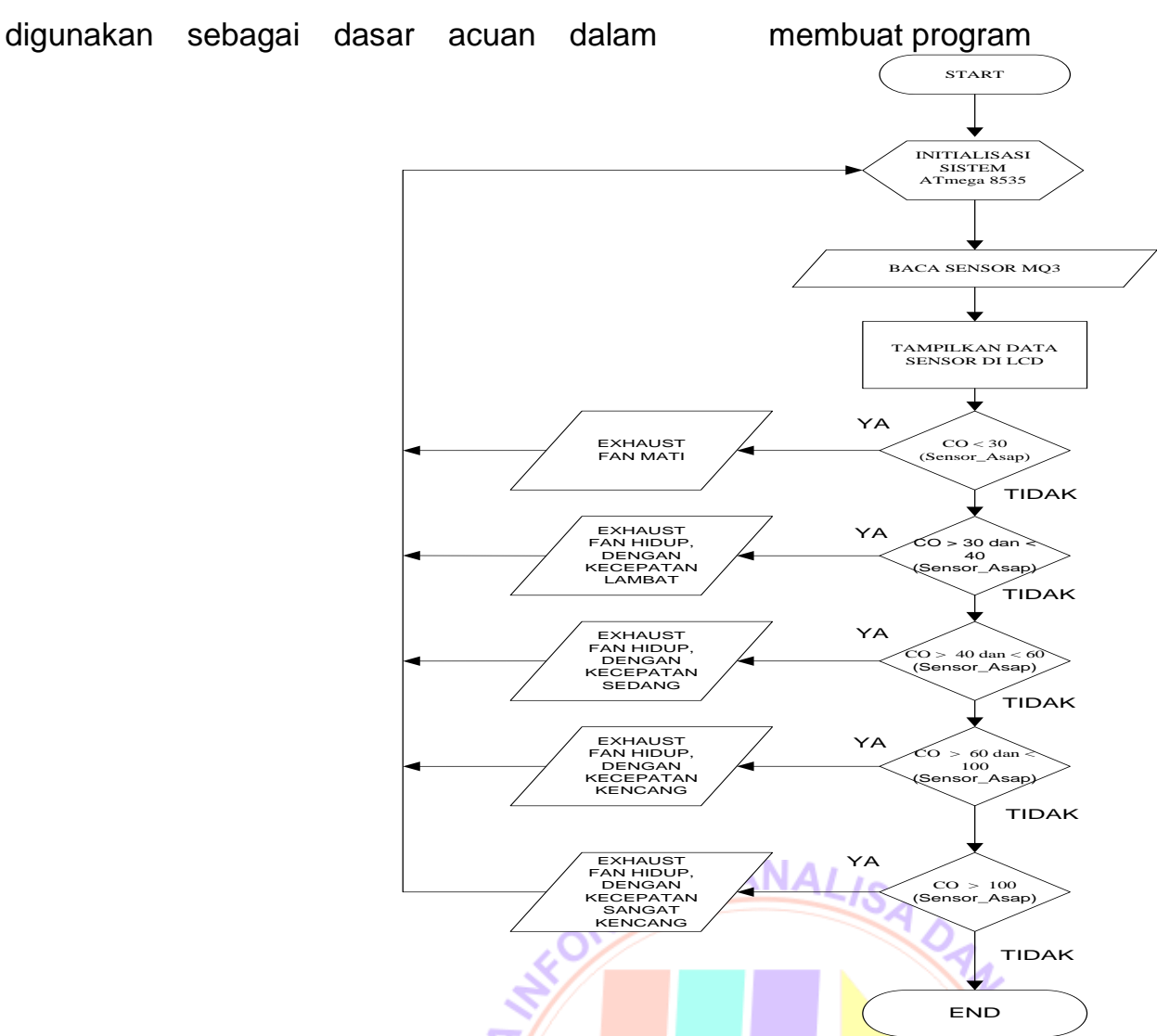

Gambar 1. Flowchat sisten

Perancangan Metode Fuzzy sugeno.Berdasarkan sistem perancangan yang akan dibuat, ada 2 variabel fuzzy yang akan dimodelkan menjadi menjadi grafik keanggotaan $^{[6]}$ yaitu :

ASAP sebagai sinyal input; terdiri atas 5 himpunan fuzzy, yaitu sangat baik, baik, agak buruk, buruk dan sangat buruk seperti gambar di bawah ini.

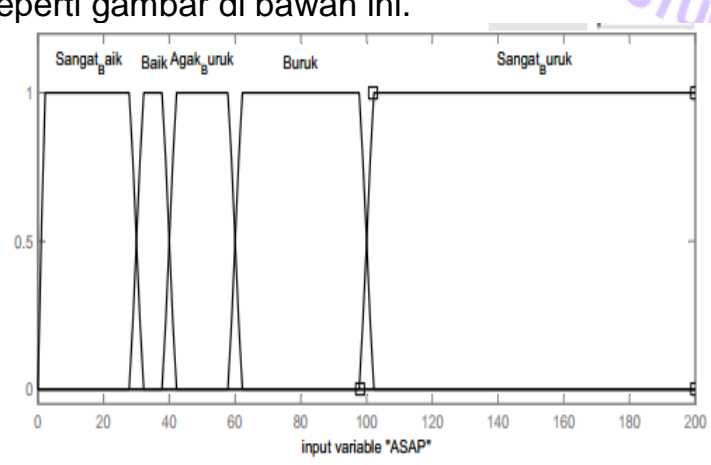

Gambar 2. Variabel Asap
Untuk menghitung derajat keanggotan himpunan input ASAP digunakan kurva trapesium dengan rumus : Fungsi keanggotan; Fungsi keanggotaan :

$$
\begin{cases}0 ; & x \leq \text { a atau } x \geq d \\ (x-a) /(b-a) ; & a \leq x \leq b \\ 1 ; & b \leq x \leq c \\ (d-x) /(d-c) ; & c \leq x \leq d\end{cases}
$$

Input $=10$ berada pada derajat keanggotaan sangat_baik maka derajat keanggotan dapat ditentukan sebagai berikut :

$\mu$ sangat_baik = 10 (sesuai dengan rumus bila $a \leq x \leq b$ maka nilainya 1 ). Maka input 10 merupakan $\mu$ sangat baik.

Dari rumus di atas maka dapatlah semua derajat keanggotaan tiap himpunan inputan ASAP. 


\begin{tabular}{cccccccc}
\hline \multicolumn{7}{c}{ Table 1 Derajat Keanggotaan tiap-tiap Himpunan ASAP } \\
\hline No & $\begin{array}{c}\text { Nilai } \\
\text { input }\end{array}$ & $\begin{array}{c}\boldsymbol{\mu} \text { Sangat } \\
\text { Baik }\end{array}$ & $\boldsymbol{\mu B a i k}$ & $\begin{array}{c}\boldsymbol{\mu} \text { Agak } \\
\text { Buruk }\end{array}$ & $\boldsymbol{\mu \text { Buruk }}$ & $\begin{array}{c}\boldsymbol{\mu} \text { Sangat } \\
\text { Buruk }\end{array}$ & $\begin{array}{c}\text { Derajat } \\
\text { keanggotaan }\end{array}$ \\
\hline $\mathbf{1}$ & 10 & 1 & - & - & - & - & Sangat Baik \\
$\mathbf{2}$ & 20 & 1 & - & - & - & - & Sangat Baik \\
$\mathbf{3}$ & 30 & 1 & 0 & - & - & - & Sangat Baik \\
$\mathbf{4}$ & 40 & - & 1 & 0 & - & - & Baik \\
$\mathbf{5}$ & 50 & - & - & 1 & - & - & Agak Buruk \\
$\mathbf{6}$ & 60 & - & - & 1 & 0 & - & Agak Buruk \\
$\mathbf{7}$ & 70 & - & - & - & 1 & - & Buruk \\
$\mathbf{8}$ & 80 & - & - & - & 1 & - & Buruk \\
$\mathbf{9}$ & 90 & - & - & - & 1 & - & Buruk \\
$\mathbf{1 0}$ & 100 & - & - & - & 1 & 0 & Buruk \\
$\mathbf{1 1}$ & 110 & - & - & - & - & 1 & Sangat Buruk \\
$\mathbf{1 2}$ & 120 & - & - & - & - & 1 & Sangat Buruk \\
$\mathbf{1 3}$ & 130 & - & - & - & - & 1 & Sangat Buruk \\
$\mathbf{1 4}$ & 140 & - & - & - & - & 1 & Sangat Buruk \\
$\mathbf{1 5}$ & 150 & - & - & - & - & 1 & Sangat Buruk \\
$\mathbf{1 6}$ & 160 & - & - & - & - & 1 & Sangat Buruk \\
$\mathbf{1 7}$ & 170 & - & - & - & - & 1 & Sangat Buruk \\
$\mathbf{1 8}$ & 180 & - & - & - & - & 1 & Sangat Buruk \\
$\mathbf{1 9}$ & 190 & - & - & - & - & 1 & Sangat Buruk \\
$\mathbf{2 0}$ & 200 & - & - & - & - & 1 & Sangat Buruk \\
\hline
\end{tabular}

Sinyal output EXHOUST_FAN; terdiri atas 5 himpunan fuzzy, yaitu mati, lambat, sedang, agak kencang dan kencang seperti gambar di bawah ini;

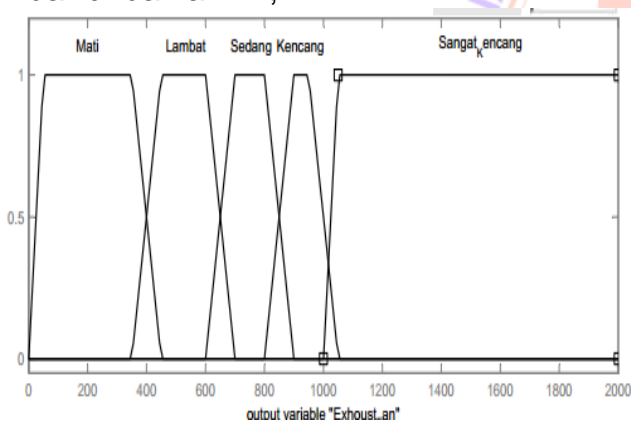

\section{Gambar 3. Variabel Exhoust Fan}

Proses Inferensi Model Sugeno. Pengolahan data dilakukan dengan menentukan variabel dan semesta pembicara dilanjutkan dengan membentuk himpunan fuzzy. Penetuan himpunan variabel dan semesta pembicara dari hasil pengambilan data dapat diperoleh pada tabel berikut :

Table 2 Penentuan Variabel dan Semesta Pembicara

\begin{tabular}{clcc}
\hline Fungsi & Nama variable & $\begin{array}{c}\text { Semesta } \\
\text { pembicara (unit) }\end{array}$ & Keterangan \\
\hline Input & ASAP & {$[0-200]$} & $\begin{array}{c}\text { Udara dalam } \\
\text { ruangan } \\
\text { Output }\end{array}$ \\
EXHOUST_FAN & {$[0-2000]$} & $\begin{array}{c}\text { Kecepatan exhaust } \\
\text { fan }\end{array}$ \\
\hline
\end{tabular}

Penetuan himpunan fuzzy di tampil kan pada table dibawah ini :

Table 3 Himpunan Fuzzy

\begin{tabular}{|c|c|c|c|c|}
\hline Fungsi & Nama variabel & $\begin{array}{c}\text { Nama } \\
\text { himpunan } \\
\text { fuzzy }\end{array}$ & $\begin{array}{c}\text { Semesta } \\
\text { pembicara } \\
\text { (unit) }\end{array}$ & interva \\
\hline Masukkan & Sensor_Asap & $\begin{array}{c}\text { Sangatbaik } \\
\text { Baik } \\
\text { Buruk } \\
\text { Agak buruk } \\
\text { Sangat Buruk }\end{array}$ & {$[0-200]$} & $\begin{array}{c}0-32 \\
28-42 \\
38-62 \\
58-100 \\
98-200\end{array}$ \\
\hline
\end{tabular}

Implementasi Motode Fuzzy Sugeno pada Pengendalian Exhoust Fan Sebagai Pembersih dan Pengatur Udara. Oleh : ${ }^{1)}$ Novriyenni, ${ }^{2)}$ Akim Manaor Hara Pardede, ${ }^{3)}$ Diky Hamdani 


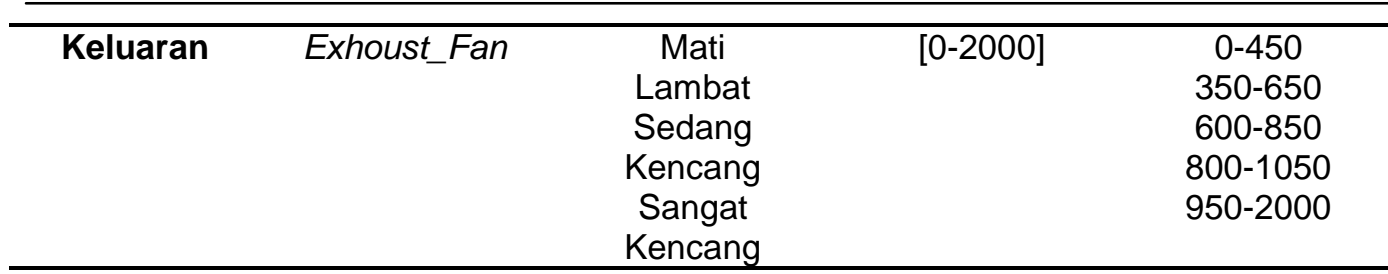

Aplikasi fungsi implikasi (aturan) untuk interferensi pengendali suhu dapat dihasilkan beberapa aturan seperti tabel berikut:

Table 4 Aturan Fuzzy untuk Sistem Kontrol Exhoust Fan

\begin{tabular}{cc}
\hline SENSOR ASAP & EXHOUST FAN \\
\hline Sangat Baik & Mati \\
Baik & Lambat \\
Agak Buruk & Sedang \\
Buruk & Kencang \\
Sangat Buruk & Sangat Kencang \\
\hline
\end{tabular}

Dari hasil inteferensi pada table 4 maka terdapat aturan fuzzy, yaitu : (1) If (ASAP is Sangat_Baik) then (Exhoust_Fan is Mati), (2) If (ASAP is Baik) then (Exhoust Fan is Lambat), (3) If (ASAP is Agak_Buruk) then (Exhoust Fan is Sedang), (3) If (ASAP is Buruk) then (Exhoust Fan is Kencang), (4) If (ASAP is Sangat_Buruk) then (Exhoust_Fan is Sangat_Kencang).

\section{Proses Perhitungan Metode Sugeno}

1. If (ASAP is Sangat_Baik) then (Exhoust_Fan is Mati) $=0$ kecepatan +0 ; $\mu$ Mati

apredikat $1=\mu$ Sangat_Baik

[30] $\cap \mu$ Mati [0]

$=\min \mu$ Sangat_Baik

$=\min (3 ; 0)$

$=0$

Nilai $z 1: z 1=0 * 30+0=0$

2. If (ASAP is Baik) then (Exhoust_Fan is Lambat) frekuensi $=1$ *kecepatan +400 ; apredikat $2 \quad=\mu$ Baik $\cap \mu$ Lambat $=\min \mu$ Baik [30] $\cap \mu$

Lambat [400]

$$
\begin{aligned}
& =\min (3 ; 40) \\
& =3
\end{aligned}
$$$$
\text { Nilai } z 2: z 2 \quad=1 * 30+400=430
$$

3. If (ASAP is Agak_Buruk) then (Exhoust_Fan is Sedang) frekuensi $=1$ * kecepatan +650 ;

Sedang

$$
\text { apredikat } 3 \quad=\mu \text { Agak_Buruk } \cap \mu
$$

[40] $\cap \mu$ Sedang [650]

$$
=\min \mu \text { Agak_Buruk }
$$

$$
\begin{aligned}
& =\min (4 ; 65) \\
& =4
\end{aligned}
$$
Nilai z3 : z3
$=1 * 40+650=690$

4. If (ASAP is Buruk) then (Exhoust_Fan is Kencang) frekuensi $=1{ }^{*}$ kecepatan +850 ;

apredikat $4=\mu$ Buruk $\cap \mu$ Kencang

$=\min \mu$ Buruk [60] $\cap \mu$ Kencang [850]

$=\min (6 ; 85)$

$=6$

Nilai $z 4: z 4=1 * 60+850=910$

5. If (ASAP is Sangat_Buruk) then (Exhoust_Fan is Sangat_Kencang) frekuensi $=0.5{ }^{*}$ kecepatan +2300 ; apredikat $5=\mu$ Sangat_Buruk $\cap \mu$

Sangat_Kencang

$=$ min $\mu$ Sangat_Buruk [100] $\cap \mu$

Sangat_Kencang [1000]

$$
\begin{aligned}
& =\min (10 ; 100) \\
& =10 \\
\text { Nilai } z 5: z 5 & =100+1000=1100
\end{aligned}
$$

Tahap Defuzzifikasi:

Nilai tegas $z$ dapat dicari menggunakan ratarata terbobot, yaitu;

$\mathrm{Z}=$

$\propto$ pred $1 * z 1+\propto$ pred $2 * z 2+\propto$ pred $3 * z 3+\propto$ pred $4 * z 4+\propto$ pred $5 * z 5$

$\propto$ pred1 $+\propto$ pred $2+\propto$ pred $3+\propto$ pred $4+\propto$ pred 5

$Z=\frac{0 * 0+3 * 430+4 * 690+6 * 690+10 * 1000}{0+3+4+6+10}=\frac{19510}{1,523}=$

848.26

\section{HASIL DAN PEMBAHASAN}

Setelah semua rangkaian yang telah selesai dirancang pada perancangan Sistem Pauengendalian Exhause FanMenggunakan Metode fuzzylogic, kemudian dilakukan penyatuan semua rangkaian yang telah selesai. Berikut adalah gambar hasil dari perancangan sistem ditunjukan oleh gambar 4:

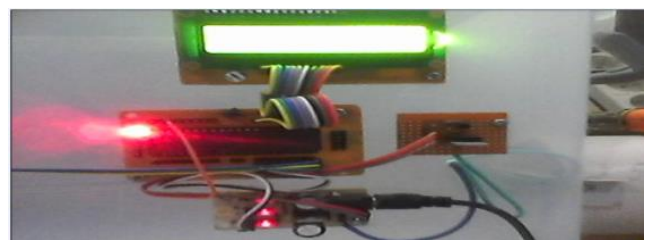

Gambar 4. Keseluruhan dari Hardware

Untuk memastikan semua perangakat telah berfungsi maka dilakukan pengujian dengan tahapan: Uji coba perangkat, pengujian rangkaian mikrokontroler ATMEGA8535, dan pengujian downloader programmer $^{[2]}$. 
Hasil Pengujian. Terdapat bebrapa kategori yaitu dengan kecepatan mati, lambat, sedang dan kencang. Pada kebersihan udara didalam ruangan terbaca dibawah $30 \%$ maka akan mengakibatkan Exhoust Fan akan mati seperti dibawah ini.

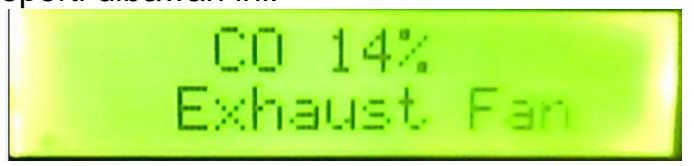

\section{Gambar 5.Monitor keadaan udara dalam ruangan sangatbaik}

Pada kecepatan lambat akan menampilkan kerusakan udara didalam ruangan antara 30\% s/d 40\% yang akan ditampilkan pada gambar

\section{Gambar 6.Monitor keadaan udara dalam baik}

Pada kecepatan sedang akan menampilkan kerusakan udara didalam ruangan antara $40 \%$ s/d $60 \%$ yang akan ditampilkan pada gambar

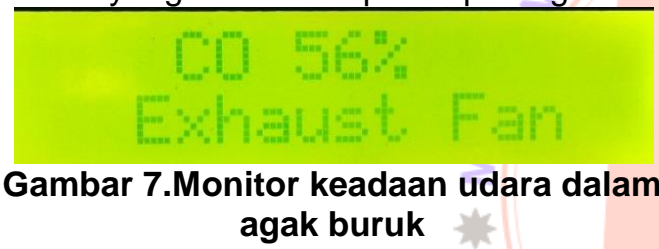

Pada kecepatan kencang akan menampilkan kerusakan udara pada sebuah ruangan antara $60 \%$ s/d $100 \%$ yang akan ditampilakan pada gambar

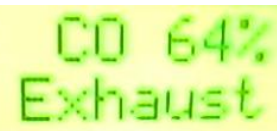

\section{Gambar 8.Monitor keadaan udara dalam ruangan buruk}

Pada kecepatan sangat kencang akan menampilkan kerusakan udara pada sebuah ruangan diatas $100 \%$ yang akan ditampilakan pada gambar

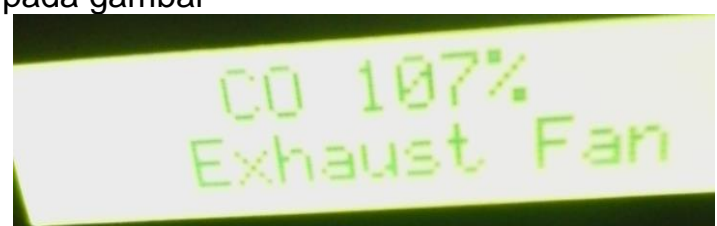

Gambar 9.Monitor keadaan udara dalam ruangan sangat buruk.

\section{KESIMPULAN}

Berdasarkan hasil penelitian dapat disimpulkan bahwa:

1. Penggunaan metode fuzzylogic,kinerja dari exhaust fandapat lebih optimal karena adanya pengaturan funsi berdasarkan kebutuhan. Proses netralisasi udara di dalam ruang dapat dilakukan lebih cepat jika karbon monoksida yang ada didalam ruangan banyak.

2. Penggunaan daya/listrik bisa lebih efisien karena sistem pembuangan asap dengan exhaust fan akan bekerja jika sesuai dengan kondisi udara pada ruangan, apabila sensor membaca bahwa karbon monoksida di ruangan mulai menurun, maka kecepatan ExhaustFan akan semakin lambat. Jadi kadar udara di ruangan akan berbanding lurus dengan kecepatan ExhaustFan.

\section{UCAPAN TERIMA KASIH}

Ucapan terimakasih penulis tujukan kepada STMIK Kaputama dan Yayasan Pendidikan Teknologi Informasi Mutiara, yang telah membantu dalam penelitian ini.

\section{DAFTAR PUSTAKA}

1. Effendy, F,A, 2015.Kendali Kecepatan Kipas Pembuangan Pada RuangKhusus Merokok Sebagai Pembersih DanPengatur Sirkulasi Udara BerbasisMikrokontroller, Skripsi Strata 1 Teknik Elektro, Universitas Telkom Bandung

2.THEndra Pitowarno. 2006. ROBOTIKA (disain,kontrol,dan kecerdasan buatan).andi, Yogyakarta.

3. Agus Naba. 2009. Belajar cepat fuzzy logic menggunakan matlab. Andi. Yogyakarta

4. Heri Adrianto. 2015.Pemograman Mikrokontroler AVR ATmega16 Menggunakan Bahasa C. Cetakan Pertama, Informatika. Bandung.

5. Syahrul .2010. MIKROKONTROLER AVR ATmega8535. Cetakan Pertama, Informatika, bandung.

6. T.Sutojo, E, dkk,.2011. Kecerdasan Buatan. Andi, Semarang. 